\title{
Critical issues in the assessment of attention deficit disorders in children
}

By: Terri L. Shelton

Shelton, T.L., \& Barkley, R.A. (1994). Critical issues in the assessment of attention deficit disorders in children. Topics in Language Disorders, 14 (4), 26-41.

Made available courtesy of Lippincott, Williams \& Wilkins http://www.lww.com/

The original publication can be found at http://journals.lww.com/topicsinlanguagedisorders/pages/default.aspx

This is not the final published version.

***Note: Figures may be missing from this format of the document

\begin{abstract}
:
A great deal of research has been directed toward understanding the general principles that govern attention. More specifically, research has sought to define the multidimensional nature of attention, the neuroanatomical system responsible for attention, and the ways in which attention can be operationally defined and measured. In addition to these investigations on attention in general, there is a large body of literature examining attention in children and in particular children who have deficits in this area. The purpose of this article is to summarize the extant literature on attention deficit disorders both with and without hyperactivity, the current diagnostic criteria, its prevalence, developmental course, and proposed etiologies. With that as a background, a conceptual framework for designing a comprehensive assessment battery is presented with specific attention to the relationship between attentional deficits and language disorders in both etiology and assessment.
\end{abstract}

Keywords: assessment; attention; attention-deficit hyperactivity disorder

\section{Article:}

Attentional problems, including attention-deficit hyperactivity disorder (ADHD), are among the most common psychological or behavioral disorders present in childhood. Because of the multi-dimensional nature of attention itself, as well as the way in which ADHD may be manifested, the diagnosis and assessment of these disorders are a complex task. In order to facilitate the assessment process, this article will review briefly the current thinking on the multidimensional nature of attention and provide an overview of the most common attentional disorder, that is, ADHD. Using this as a framework, guidelines for designing a comprehensive assessment battery will then be presented. Particular attention will be directed toward the linkages between ADHD and language disorders.

\section{ATTENTION}

Despite over a century of theorizing and study, the concept of attention remains as ambiguous and controversial today as it did when William James attempted to describe it nearly 100 years ago (James, 1898). This is undoubtedly the supreme critical issue in assessing attention - the determination of its meaning and how it is to be operationalized. What is attention? 
Attention in its broadest sense refers to conditional relationships between behavior and environment. Here both behavior and environment are taken to mean activities occurring both externally (outside the skin) and internally (within the body). Attention does not refer to either environmental events nor the actions of the organism alone but to their relationships. Thus, attention refers to the reactivity or responsivity of the organism to events (objects, actions, and their properties) in its environment. Attention is not a thing nor an entity or action but a relationship - a correlation between or among events and reactions to them (Skinner, 1953). The study of attention is the investigation of these eventbehavior correlations and, more specifically, the variables or factors of which these correlations seem to be a function (i.e., type of stimulus, nature of the response, characteristics of the organ-ism and the context, etc.). The evaluation of attention is thus inherently contextually dependent and so must be the clinical assessment of attention and its deficiencies as well.

Many have noted that attention is multidimensional in nature (Hale \& Lewis, 1979; James, 1898; Mesalum, 1990; Mirsky, 1987; Posner, 1988; Titchener, 1924) with there seeming to be a consensus on the following components or dimensions. Each one refers to a different facet of event-response relations. One dimension is arousal or alertness, which seems to refer to the overall level of activity/responsivity of the organism within the general environment. A second dimension is impulsivity, which typically implies the time between the event and the individual's response to it. Many theorists, however, would include in the concept of impulsiveness the quality of the response, which is to say its accuracy or correctness in fulfilling the purpose of the response. Fast-inaccurate responding, then, is impulsive responding. Another dimension of attention is selective or focused attention, which likely refers to the particular spatiotemporal facets of certain events to which the individual selectively responds relative to all the other events to which the individual could potentially respond. A fourth dimension is sustained attention or persistence of action, which refers to the temporal period over which the response, or more likely the series of particular responses, is maintained to a particular event or series of such particular events. It deals with the duration of the action or the issue of how long the organism maintains its responses to some event(s). Finally, there seems to be some agreement that there is a shift dimension of attention that is the cessation of responding to one event or series of events with a change to responding to a different event or event series.

Other components of attention over which there is less agreement are as follows:

- divided attention, where the individual must pay attention and respond to two different tasks simultaneously;

- search, which involves the strategy employed by the individual to inspect and evaluate the environmental event; and

- encode, which refers to the capacity to retain information in working or short-term memory (see Barkley, 1994; Cooley \& Morris, 1990).

Such constructs overlap with those of memory and executive functions, making it unclear as to whether they are actually components of attention or components of these other psychological constructs.

Each of these dimensions appears to have a separate neuroanatomical system responsible for its existence, though there is hardly perfect agreement on the specific regions/ systems involved. Arousal or alertness is often assigned to the brainstem reticular activating system, selection or focus to the posterior cortical-subcortical sensory-processing pathways, impulsivity and sustained attention to the mesial 
orbital prefrontal regions of the cortex and its interconnections to the limbic system, and shift to the prefrontal dorsolateral regions (Fuster, 1989; Mesalum, 1990; Mirsky, 1987; Posner, 1988). Nevertheless, these systems/dimensions of attention interact and coordinate their functions such that disturbances in one aspect of attention are likely to have an impact on the other dimensions.

Implicit throughout any discussion of attention is the tacit acknowledgement of the interaction of two fundamental brain functions/systems to achieve these dimensions of attention. These two systems are typically known as the behavioral activation system, which seems to respond to signals of impending reinforcement, reinforcement itself, and escape/avoidance of aversive consequences, and the behavioral inhibition system, which seems to respond to signals of impending punishment, punishment itself, and frustrative nonreward (see Gray, 1982; Quay, 1988). This is why any discussion of attention (to what we respond and how) is hopelessly confounded with issues of motivation (why we respond to events at all). This interrelation has led some to propose that the problems some children have with certain types of attention may be the result of impairments in these motivational systems (Barkley, 1990; Douglas, 1983; Quay, 1988).

Despite some consensus on these dimensions of attention and their anatomical localization, there is often controversy as to how these dimensions are to be operationally defined and measured. Different models or theories of attention currently exist providing quite different paradigms for the scientific study of attention. Most notable among the current models are the neuropsychological (Mesalum, 1990; Mirsky, 1987; Posner, 1988), information processing (Shiffrin \& Schneider, 1977; van der Meere \& Sergeant, 1988), and behavioral (McIlvane, 1994; Skinner, 1953) paradigms. Each strives to account for different dimensions of attention and the variables that affect it. These distinctions pose another critical issue in the assessment of attention deficits. That is, the selection of measures and their interpretation are highly dependent upon which of these schools of thought one holds and what the purpose of the assessment happens to be (see Barkley, 1994, pp. 71-76, for a comprehensive discussion of these paradigms).

Given that attention is multidimensional, we might expect to encounter children who have deficits primarily in one dimension or component and less so or not at all in the others. This is quite probably the case in clinical practice. However, we know very little about the nature of deficiencies in some components of attention, the best methods to assess them, and the ways in which our assessments lead to differential treatment recommendations as compared to children with deficits in the other components.

Far and away the greatest research has been on children hypothesized to have deficits in the impulsive and sustained components of attention. Such children have been referred to as hyperactive or hyperkinetic, attention deficit disorder (ADD), and attention deficit hyperactivity disorder (ADHD) (American Psychiatric Association, 1968, 1980, 1987). Thousands of studies exist on these children, and so they will be the focus of much of the discussion that follows. More recently, it has been suggested that children who have ADD without hyperactivity (are predominantly inattentive and not hyperactiveimpulsive) may have their deficit in the select/focus component of attention, whereas those with ADD with hyperactivity, or ADHD, have their principal problem in the response inhibition component (Barkley, 1990; Barkley, Grodzinsky, \& DuPaul, 1992; Goodyear \& Hynd, 1992). Far less information is available on those with ADD without hyperactivity, and so they receive less attention here.

\section{ATTENTION-DEFICIT HYPERACTIVITY DISORDER (ADHD)}

Affecting approximately $3 \%$ to $5 \%$ of the general child population, ADHD is characterized by extreme 
difficulties with inattention, hyperactivity, and impulsivity that exceed developmental expectations. With regard to attention, research to date suggests that children with ADHD have their greatest difficulties with the particular dimension of attention that relates to response inhibition and sustaining attention to tasks, often known as vigilance (Barkley, 1990; Douglas, 1983). These difficulties are most dramatic with respect to dull, boring, repetitive tasks (Luk, 1985).

Intertwined with poor sustained attention is a deficiency in inhibiting behavior in response to situational demands, or impulsivity. Like the previous discussion on attention, impulsivity is also multidimensional in nature (Milich \& Kramer, 1985). The problem is often defined as a pattern of rapid, inaccurate responding to tasks (Brown \& Quay, 1977). However, it may also refer to poor sustained inhibition, poor delay of gratification, or impaired adherence to commands to regulate or inhibit behavior in social contexts (Kendall \& Wilcox, 1979; Rapport, Tucker, DuPaul, Merlo, \& Stoner, 1986).

Hyperactivity has been a hallmark of the diagnosis. Children with ADHD have been found to be more active, restless, and fidgety than same-aged peers (Porrino, et al., 1983). The problem with hyperactivity appears to reflect a deficiency in response inhibition. That is, those with ADHD are hyperresponsive to their environment due to a low inhibitory threshold or slowness to inhibit that results in stimuli eliciting prepotent responses. Hence, they are more active. As with poor sustained attention, however, there are significant situational fluctuations in this symptom (Luk, 1985). This situational variability suggests that it is the failure to regulate activity level to setting or task demands that may be problematic (Routh, 1978). Recent studies also note that it may be the pervasiveness of the hyperactivity across settings that separates ADHD from other diagnostic categories of children (Taylor, 1986).

In addition to these symptoms, there is growing evidence that children with ADHD also have difficulties following rules (Barkley, 1981). This may be evidenced as noncompliance with parental and teacher commands or an inability to delay reward or gratification. Care is taken here to exclude poor rulegoverned behavior that may stem from sensory handicaps (i.e., deafness), impaired language comprehension, or defiance or oppositional behavior. Like the other symptoms, rule-governed behavior is a multidimensional construct having various components (Zettle \& Hayes, 1982). It remains to be shown which of these are specifically impaired in these children. How-ever, it appears that these children have the most difficulty with tracking or the sustained correspondence of behavior to specific rules.

\section{Diagnostic criteria}

The changing names given to attentional disorders (e.g., minimal brain dysfunction, hyperkinesis) and the different behaviors that have been highlighted have been reflected in concomitant changes in diagnostic criteria. In 1980, two types of attention deficit disorder were identified: (1) attention deficit disorder with hyperactivity $(\mathrm{ADD} /+\mathrm{H})$ and attention deficit disorder without hyperactivity $(\mathrm{ADD} /-\mathrm{H}$; American Psychiatric Association, 1980). In 1987, the diagnostic criteria were revised yet again (American Psychiatric Association, 1987). The new criteria included inclusionary and exclusionary criteria, recognized the situational variability of behaviors, and strongly stressed the need for documenting that symptoms exceeded developmental expectations. At the time, however, little re-search supported the existence of two distinct subtypes. As a result, ADD without hyperactivity was no longer listed as a sub-type. Instead, the label of undifferentiated attention deficit disorder (UADD) was used to characterize those who manifested difficulties primarily with inattention, without hyperactivity and impulsivity. 
In 1994, the publication of DSM-IV represents still another change in diagnostic classification. This change reflects the increasing empirical evidence that attention deficits and hyperactivity-impulsivity are two distinct dimensions, differing in level of impairment, the presence of comorbid features, social and cognitive development, and developmental course. For example, it appears that those children whose primary difficulties lie in impulsivity-hyperactivity have significantly more difficulties with peer relations, conduct problems, and substance use and abuse, and greater risk for antisocial personality in adulthood (Barkley, Fischer, Edelbrock, \& Smallish, 1990). In contrast, those whose primary difficulties are with inattention more closely resemble children with learning disabilities in their academic difficulties (Carlson, 1986) and associated behavioral difficulties.

In the new proposed diagnostic criteria, the symptoms of inattention, impulsivity, and hyperactivity are still present. However, these may occur separately or concurrently resulting in four subtypes:

1. attention-deficit hyperactivity disorder, predominantly inattentive type;

2. attention-deficit hyperactivity disorder, predominantly hyperactive-impulsive type;

3. attention-deficit hyperactivity disorder, combined type; and

4. attention-deficit hyperactivity disorder not otherwise specified (for disorders with prominent symptoms of attention deficit or hyperactivity-impulsivity that do meet criteria for either of the above; Shaywitz, this issue).

\section{Speech and language development in children with ADHD}

The percentage of children experiencing some delay in the onset of talking may be somewhat greater for children with ADHD (6\% to 35\%) than for those without ADHD (2\% to 5.5\%; Hartsough \& Lambert, 1985; Stewart, Pitts, Caria, \& Dieruf, 1966; Szatmari, Offord, \& Boyle, 1989). However, other studies, using clinic-referred populations have found no delays (Barkley, DuPaul, \& McMurray, 1990). More conclusive evidence exists regarding the observation that children with ADHD are likely to talk more than those without ADHD, especially during spontaneous conversation (Barkley, Cunningham, \& Karlsson, 1983; Zentall, 1989). Children with ADHD may not only be motorically overactive, but verbally as well. In contrast to their increased frequency in spontaneous speech, children with ADHD may be less verbal and more dysfluent in situations when they must organize and generate their speech (Hamlett, Pelligrini, \& Conners, 1987; Zentall, 1985). While not all children with ADHD have these speech and language difficulties, the increased risk of language difficulties in these areas may be due to difficulties in higher order cognitive processes involved in organizing and monitoring behavior directed toward a future goal, known as executive processing (Pribram, 1971). According to Rapin and Wilson (1978), "Except in rare instances of extreme environmental deprivation [language disorders are almost always] the consequence of neurological dysfunction" (p. 13). It may be that the deficiencies in prefrontal cortex functioning that have been hypothesized to contribute to the ADHD symptoms of inattention, a lack of inhibition, and overactivity may also contribute to the deficiencies in syntax, fluency, and production in these situations (Chelune, Ferguson, Koon, \& Dickey, 1986; Fuster, 1989; Heilman, Voeller, \& Nadeau, 1991; Zametkin \& Rapoport, 1986).

Depending on the definition, approximately $25 \%$ to $50 \%$ of the children with ADHD will have at least one type of learning disability, either in math, reading, or spelling (August \& Garfinkel, 1990; Barkley, 1990; Dykman \& Ackerman, 1991; Safer \& Allen, 1976). Some evidence exists that early ADHD may predispose toward a greater risk of later reading problems in children (Ferguson \& Horwood, 1992). It is 
unclear whether it is the early problems with attention and inhibition that create this risk or the problems with early language development, particularly verbal mediation.

Certainly, children with early stable behavior problems, especially hyperactivity and aggressiveness, are more often delayed in their verbal abilities than are children without such behavior problems (McGee, Silva, \& Williams, 1984; Weithorn \& Kagen, 1978). Likewise, children with early deficits in language development, particularly abstract reasoning, were more likely to have problems with poor behavioral inhibition and aggressiveness (Richman \& Lindgren, 1981). Of even greater relevance to the present article have been recent findings that children diagnosed with significant speech and language disorders have considerably greater risks for psychiatric disturbance than do children with normal language development (Beitchman, Hood, \& Inglis, 1990; Beitchman, Nair, Clegg, Ferguson, \& Patel, 1986; Cantwell \& Baker, 1985; Cantwell, Baker, \& Mattison, 1980) with the most common disorder being ADHD (17\%-38\%). Thus, there is considerable, albeit incomplete, overlap between impulsive, hyperactive behavior, or ADHD, and early language disorders.

Another link between ADHD and language disorders can be found in a recent theory that ADHD represents a disorder of response inhibition that leads to deficiencies in a number of executive functions, including the use of self-directed speech for self-regulation and the crosstemporal organization of behavior (Barkley, in press). From this perspective, a developmental impairment in response inhibition and delayed responding is associated with a delay in the internalization of language and its use in selfregulation. As a result, children with ADHD are more likely to have difficulties in higher order, or executive, language functioning such as verbal mediation and guidance of behavior for planning and goal accomplishment.

\section{ASSESSMENT}

The clinical assessment of attention disorders is fraught with numerous problems and critical issues, not the least of which is the lack of knowledge about what constitutes a disorder in each of the different components of attention. Another critical problem is the lack of adequate instruments and tasks for assessing each component of attention. (See Barkley, 1994, pp 78-79, for a tabular presentation of this and the following points.) Interviews and rating scales typically do not provide a fine-grain analysis of attention that permits its separation into the components described earlier (Barkley, 1994). Parent and teacher rating scales of behavior often identify only one dimension of attention, suggesting that they tend to judge attentional problems in a very general or global manner. Even so, these ratings often contain items that pertain to hyperactive and impulsive behavior as well.

Laboratory measures, psychological tests, and direct-observation coding systems are somewhat more helpful in differentiating among the components of attention. However, most measures fit for clinical purposes, such as commercially available Continuous Performance Tests (CPAs: Conners, 1985), tend to confound these components of attention to some degree. They are also likely to be confounded by other psycho-logical abilities, such as intelligence, memory, verbal or language abilities, and executive functions. This makes them quite impure and difficult to interpret in any straightforward manner as measuring only one type of attention. A further problem is their relatively low to moderate ecological validity, or the degree to which they predict attentional problems in natural settings such as school (Barkley, 1992). The assessment of those aspects of attention (inhibition and sustained attention) related to ADHD is, perhaps, the best-developed approach to date, and so these will be discussed here as a suggested paradigm. 
The very nature of ADHD demands a comprehensive approach to assessment. While it may be possible to choose a set of measures to be used as the core of a standard battery, others have suggested that a decision-making or problem-solving model (e.g., Fowler, 1992; Kanfer \& Saslow, 1969) may be more useful in order to accommodate the changing diagnostic criteria for ADHD, the various characteristics that may be associated with ADHD, and the child's characteristics (e.g., chronological age, developmental functional levels).

In addition, the purpose of the assessment and the type of decision being made must be considered. In some cases, the goal may be to screen children in need of further assessment. In others, the purpose may be to confirm or disconfirm the diagnosis. Once the diagnosis has been confirmed, assessment may be used to examine the degree to which ADHD affects the child's academic achievement and other areas of development (Fowler, 1992). Finally, some consideration should be given as to whether the assessment is "descriptive" (documenting baseline levels) or "prescriptive" (planning treatment or evaluation of treatment efficacy).

A comprehensive battery must include measures that tap the particular behaviors listed in the diagnostic criteria (e.g., measures of attention, impulsivity, hyperactivity). In addition, because of the frequency with which other behaviors and difficulties accompany ADHD, an assessment battery should include measures not only of ADHD symptomatology but of other behaviors and skills as well (e.g., peer relations, anxiety, depression, oppositional or conduct problems, academic achievement, and executive language development).

The situational variability of ADHD demands multiple methods of assessment relying on several informants who have knowledge of the child in different settings. Parent, teacher, and perhaps child selfreport ratings are necessary in order to examine the pervasiveness and severity of symptoms. In addition, because the severity of the symptoms must be developmentally inappropriate for the child's age and gender, the measures must have appropriate normative data.

With these caveats in mind, those assessment instruments that have demonstrated clinical utility in the assessment of ADHD will be reviewed briefly. More detailed information on specific instruments are reviewed elsewhere (Barkley, 1981, 1988, 1990; Shelton \& Barkley, 1993).

\section{Interviews}

The assessment of ADHD children naturally begins with an in-depth interview with the parent, followed by interviews with the child, and later, his or her teacher. While informal or semistructured interviews can be quite useful, there are a number of well-established structured interviews that offer comprehensive formats for evaluating not only ADHD symptomatology but related behaviors as well. The work by the federally funded national resource centers for the study of ADHD has recommended using such an established interview format. For example, the Diagnostic Interview Schedule for Children (DISC; Costello, Edelbrock, Kalas, Kessler, \& Klaric, 1982) includes formats for parents as well as children. Other interviews have been developed solely for children's responses such as the Interview Schedule for Children (ISC; Kovacs, 1982) and the Children's Assessment Schedule (CAS; Hodges, McKnew, Cytryn, Stern, \& Kline, 1982). The inter-view with the child is primarily used to gain a general impression of his or her appearance, language functioning, and social skills with an adult, and to establish rapport. All these interviews require some familiarity with DSM-III-R criteria. Changes in 
the DSM-IV criteria also will need to be integrated. Nevertheless, these interviews provide an excellent means for examining both ADHD and comorbid conditions.

In addition to the areas covered by these structured psychiatric interviews, there should be a review of developmental milestones, unusual medical problems, and so forth. Details of the child's school history and then the history of any learning or psychiatric problems in the parents, siblings, grandparents, aunts and uncles, and cousins should be reviewed. Generally, the children should be questioned about their view of general interests in play and school, academic problems, difficulties with peers, family relations and conflicts, and the reason they have been referred for this evaluation.

The interview with the teacher should include questions about the child's current academic achievement, social functioning with classmates, and general classroom behavior. Attention should be directed toward the child's attention to tasks, impulse control in various situations, activity level, and ability to follow rules and instructions. Differences in behavior based on academic subject, teacher, class size, and so forth should be described. Any additional information concerning child personality, emotional difficulties, and family problems should be obtained.

\section{Child and parent behavior rating scales}

Behavior ratings offer many advantages in the assessment process. Their convenience, applicability to multiple informants (e.g., parents, teachers, children), ability to gather information across long time intervals, and large pool of normative data to establish developmental deviancy have led to their widespread adoption in clinical practice. There are several reviews of rating scales (see Barkley, 1988), but a few of the instruments are reviewed below.

The revised Child Behavior Checklists (Achenbach, 1991) have proven to be a good adjunct to the structured interviews. There are now comparable forms for parents and teachers of children ages 4 to 16 . There is still the form for parents of children ages 2 to 3 and a child self-report form as well. The scores provide a profile of the child's behavior relative to other children the same age and sex for a wide range of behaviors including both internalizing (e.g., depression, anxiety) and externalizing (e.g., conduct) problems as well as social competence.

For examining ADHD symptomatology specifically, the Conners Parent and Teacher Rating Scales, revised (Goyette, Conners, \& Ulrich, 1978) provides a profile of child behavior in five categories from ages 3 through 17: (1) conduct problems, (2) learning problems, (3) psychosomatic problems, (4) impulsivity - hyperactivity, and (5) anxiety. Edelbrock (1985) also has developed a rating scale comprised of items from the Child Behavior Checklist that assesses attention and overactivity that should be quite helpful in using the new DSM-IV criteria.

Other measures of ADHD symptomatology with normative data include the Werry-Weiss-Peters Activity Rating Scale (see Barkley, 1981; Werry \& Sprague, 1970), the ADHD Rating Scale (DuPaul, 1991), and the Comprehensive Teacher Rating Scale (ACTeRS; Ullmann, Sleator, \& Sprague, 1984).

In view of the relatively high incidence of marital discord, major affective disorder, disruption in parenting abilities, and general parental psychopathology among the parents of ADHD children, as well as their demonstrated bearing on treatment responsiveness and adolescent outcome, it is valuable to include parent self-report measures as part of the assessment of ADHD children. The Symptom 
Checklist 90, revised (SCL-90R; Derogatis, 1986), Beck Depression Scale (Beck, Rush, Shaw, \& Emery, 1979), Locke_-Wallace Marital Adjustment Scale (Locke \& Wallace, 1959), and Parenting Stress Index (Abidin, 1986) have proven useful.

\section{Laboratory measures}

Laboratory measures of sustained attention, impulsivity, and activity level are becoming more widely used. However, because many of these instruments lack appropriate normative data or established reliability and validity, they should not be used in isolation from interviews and rating scales.

Nevertheless, with additional normative data, laboratory tests of ADHD symptoms may become a useful part of a comprehensive battery.

\section{Vigilance and sustained attention}

One of the most widely used instruments for assessing vigilance has been the continuous performance test (CPT). Numerous versions exist (e.g., Conners Continuous Performance Task, Conners, 1985; Gordon Diagnostic System [GDS], Gordon, 1983; Klee \& Garfinkel, 1983), but most involve having the child observe a screen while individual letters or numbers are projected onto a screen at a rapid pace. 'The child is required to press a button when a certain stimulus appears. While intuitively appealing, the research on the clinical utility of these measures remains to be established with there being a high degree of false-negative results, or the classification of a child as normal who has an attentional deficit (e.g., Barkley \& Grodzinsky, 1994; DuPaul, Anastopoulos, Shelton, Guevremont, \& Metevia, 1992;

Trommer, Hoeppner, Lorber, \& Armstrong, 1988). These instruments may be most helpful when their results are abnormal, in which case there is an $80 \%$ to $100 \%$ chance the child has an attentional deficit. They are also helpful in evaluating responses to stimulant medication.

\section{Impulsiveness}

Several laboratory methods have been used in assessing impulsiveness in ADHD children. The most well known of these is the commission score on the CPTs discussed above. Another measure commonly used in research has been the Matching Familiar Figures Test (MFFT; Kagan, 1966). The measure appears to significantly discriminate ADHD from normal children (Campbell, Douglas, \& Morgenstern, 1971), as well as aggressive versus nonaggressive ADHD groups (Milich, Landau, \& Loney, 1981), and is sensitive to stimulant drug effects (Barkley, 1977). Many studies have used the Porteus Mazes to evaluate planning and impulse control in ADHD children (Douglas, 1983). While normative data are outdated for this instrument, it has been shown to successfully discriminate ADHD and normal children and to be sensitive to stimulant drug effects (Barkley, 1977). A major problem with all of these instruments is their low intercorrelation, implying that each is measuring a different facet of impulsivity (Milich \& Kramer, 1985). The behavioral ratings of impulsivity appear to have more diagnostic utility at this time.

\section{Activity level}

Numerous measures of activity level have been employed in research, spanning a variety of types of activity, such as motion of arms, legs, or trunk; locomotion; total body movement; and so forth (Tryon, 1984). Their lack of normative data, low reliability in some cases, low intercorrelation, poor relationship to parent and teacher ratings of activity level, and inability to take into account situational influences have argued against their use in clinical diagnosis or treatment planning.

\section{Direct observational procedures}


Various behavioral observation codes have been used to assess ADHD symptoms as well as potential behavior problems that often accompany ADHD. Notable among these are the systems developed by Jacob, O'Leary, and Rosenblad (1978) and Abikoff, Gittelman-Klein, and Klein (1977) for classroom observations, and Roberts (1987) and Barkley (1990) for clinic analogue situations. These coding systems record behaviors such as off-task, out-of-seat, fidgets, locomotion, vocalizations, and attention shifts; behaviors noted to occur more often in children with ADHD. The child is typically observed while working on academic-like tasks in the clinic or while performing actual school work in the classroom.

\section{Psychological and educational tests}

A comprehensive assessment battery should include either a direct assessment of the child's intellectual and academic abilities or at the very least, a review of recent academic/intellectual testing. This information is necessary because in order to make a diagnosis, the symptoms must be significantly different from what would be expected of other children of the same developmental age. If a child has some developmental delays, these must be taken into account in establishing expectations for behavior. Second, these measures should be included because of the frequency with which children with ADHD experience intellectual delays, academic underachievement, and language problems as well as specific learning disabilities. Finally, this information is helpful in determining whether the child's difficulties may be indicative of another difficulty. For example, children with auditory comprehension disorders (e.g., Wilson \& Risucci, 1986) including difficulties with auditory discrimination, perception, and sequential memory may behave in ways that are similar to children with ADHD (e.g., not following directions, being inattentive, having poorer performance in large-group situations). In some cases, additional neuropsychological testing may be necessary.

For preschool-aged children, the Stanford-Binet Intelligence Scale, Fourth Edition (Thorndike, Hagen, \& Sattler, 1986) or the Wechsler Preschool and Primary Scales of Intelligence, revised (Weschler, 1989) can be used to obtain an estimate of general cognitive abilities as well as other areas such as verbal reasoning, abstract/visual reasoning, and memory. For older children, the Wechsler Intelligence Scale for Children, third edition (WISC-Ill; Weschler, 1991) is appropriate. These measures should not be used, however, to diagnose the presence or absence of ADHD.

For example, previous studies have suggested that the Weschler Intelligence Scale for Children-Revised (WISC-R; Wechsler, 1974) may provide information on a child's distractibility and/or inattention through the freedom from distractibility (FD) factor (e.g., Arithmetic, Digit Span, and Coding subtests; Kaufman, 1979). However, the factor does not consistently discriminate between children with or without ADHD (Greenblatt, Mattis, \& Trad, 1991; Hodges, Horwitz, \& Kline, 1982) and may be measuring more than a pure factor of distractibility (see Wielkiewicz, 1990, for a review). Additional research is needed using the revised third edition of the WISC-III (Wechsler, 1991) to establish the utility of the new FD factor.

For academic achievement, and more specifically for predicting achievement from intellectual abilities, the Woodcock - Johnson Psychoeducational Battery, revised (WJ-R; Woodcock \& Johnson, 1990) and the Weschler Individual Achievement Tests (WIAT; Weschler, 1991) can be quite helpful. Used in conjunction with the cognitive ability index generated from the WJ-R and/or WISC-III, respectively, these two measures can be useful in examining the degree to which the child's academic ability may be affected by the ADHD and whether additional learning disabilities may be present. 
Although most general intellectual assessment instruments provide scores for some verbal factors, these, by no means, constitute a comprehensive language assessment. Nevertheless, an examination of the subtest score pattern, along with individual achievement tests, can provide some indication of whether more extensive speech-language evaluations are necessary. Additional evaluations using instruments such as the Goldman-Fristoe-Woodock Auditory Skills Battery (Goldman, Fristoe, \& Woodcock, 1986) may be helpful in determining if the child's difficulties may be due to more of an auditory-processing problem than to ADHD. Because of the potential overlap between ADHD and these auditory processing or "executive function" difficulties, it may be prudent to include a brief screening of speech-language functioning such as the Speech-Language Identification Questionnaire (SLIQ; Tortolani, Murray, Risucci, \& Wilson, 1987) as part of the battery.

The assessment of attention disorders, such as ADHD, like any class of child behavioral difficulties, requires careful planning. Because of the multidimensional nature of the attention disorders and their related features, no one approach will be sufficient. Each method of assessment offers particular strengths as well as limitations. Yet, the problems inherent in each can be partially addressed by employing multiple methods from several sources across different settings and informants. At the very least, the assessment should include not only the traditional methods of parental and child interviews, but also standardized child behavior rating scales; psychometric measures of attention, intelligence, and achievement; and direct behavioral observations of the attentional symptoms in natural or analogue settings. Promising laboratory measures of sustained attention may soon make it possible to evaluate more objectively ADHD symptoms in clinical settings. Finally, as research into the nature of the deficits in attention disorders progresses and the diagnostic criteria become more refined, assessment methods will need to mirror these changes as well.

\section{REFERENCES}

Abidin, R.R. (1986). The Parenting Stress Index (2nd ed.). Charlottesville, VA: Pediatric Psychology Press.

Abikoff, H., Gittelman-Klein, R., \& Klein, D. (1977). Validation of classroom observation code for hyperactive children. Journal of Consulting and Clinical Psychology, 45, 772-783.

Achenbach, T.M. (1991). Manual for the Revised Child Behavior Checklist. Burlington, VT: Author.

American Psychiatric Association. (1980). Diagnostic and statistical manual of mental disorders (3rd ed.). Washington, DC: Author.

American Psychiatric Association. (1987). Diagnostic and statistical manual of mental disorders (3rd ed., rev.). Washington, D.C.: Author.

American Psychiatric Association. (1993). Diagnostic and statistical manual of mental disorders (4th ed. draft). Washington, D.C.: Author.

August, G.J., \& Garfinkel, B.D. (1990). Comorbidity of ADHD and reading disability among clinicreferred children. Journal of Abnormal Child Psychology, 18, 29-45.

Barkley, R.A. (1977). A review of stimulant drug research with hyperactive children. Journal of Child Psychology and Psychiatry, 18, 137-165.

Barkley, R.A. (1981). Hyperactive children: A handbook for diagnosis and treatment. New York, NY: Guilford.

Barkley, R.A. (1988). Child behavior rating scales and checklists. In M. Rutter, H. Tuma, \& I. Lann (Eds.), Assessment and diagnosis in child psychopathology (pp.113-155). New York, NY: Guilford. 
Barkley, R.A. (1988). Attention deficit-hyperactivity disorder. In E. Mash \& L. Terdal (Eds.), Behavioral assessment of childhood disorders (2nd ed.). New York, NY: Guilford.

Barkley, R.A. (1990). Attention deficit hyperactivity disorder. New York, NY: Guilford.

Barkley, R.A. (1992). The ecological validity of laboratory and analogue assessments of ADHD symptoms. Journal of Abnormal Child Psychology, 19, 149-178.

Barkley, R.A. (in press). Delayed responding and attention deficit hyperactivity disorder: A unified theory. In D.K. Routh (Ed.), Disruptive behavior disorders in children: Essays in honor of Herbert Quay. New York, NY: Plenum.

Barkley, R.A. (1994). The assessment of attention in children. In G. R. Lyon (Ed.), Frames of reference for the assessment of learning disabilities: New views on measurement issues. Baltimore, MD: Brookes Publishing.

Barkley, R.A., DuPaul, G., \& McMurray, M. (1990). A comprehensive evaluation of attention deficitdisorder with and without hyperactivity as defined by research criteria. Journal of Consulting and Clinical Psychology.

Barkley, R.A., Fischer, M., Edelbrock, C.S., \& Smallish, L. (1990). The adolescent outcome of hyperactive children diagnosed by research criteria: I. An 8 year prospective follow-up study. Journal of the American Academy of Child and Adolescent Psychiatry, 29, 546-557.

Barkley, R.A., Cunningham, C., \& Karlsson, J. (1983). The speech of hyperactive children with their mothers: Comparisons with normal children and stimulant drug effects. Journal of Learning Disabilities, 16, 105-110.

Barkley, R.A., \& Grodzinsky, G. (1994). The utility of neuropsychological tests of frontal lobe functions in the diagnosis of attention deficit disorders. Manuscript submitted for publication, Worcester, MA: University of Massachusetts Medical Center.

Barkley, R.A., Grodzinsky, G., \& DuPaul, G.J. (1992). Frontal lobe functions in attention deficit disorder with and without hyperactivity: A review and research report. Journal of Abnormal Child Psychology, 20, 163-188.

Beck, A.T., Rush, A.J., Shaw, B.F., \& Emery, G. (1979). Cognitive therapy for depression. New York, NY: Guilford.

Beitchman, J.H., Hood, J., \& Inglis, A. (1990). Psychiatric risk in children with speech and language disorders. Journal of Abnormal Child Psychology, 18, 283-296.

Beitclunan, J.H., Nair, R., Clegg, M., Ferguson, B., \& Patel, P.G. (1986). Prevalence of psychiatric disorders in children with speech and language disorders. Journal of the American Academy of Child Psychiatry, 25, 528-535.

Brown, R.T., \& Quay, L.C. (1977). Reflection-impulsivity of normal and behavior-disordered children. Journal of Abnormal Child Psychology, 5, 457-462.

Campbell, S.B., Douglas, V.I., \& Morganstern, G. (1971). Cognitive styles in hyperactive children and the effect of methylphenidate. Journal of Child Psychology and Psychiatry, 12, 55-67.

Cantwell, D.P., \& Balcer, L. (1985). Psychiatric and learning disorders in children with speech and language disorders: A descriptive analysis. In K.D. Gadow (Ed.), Advances in learning and behavioral disabilities (Vol. 4). Greenwich, CT: JAI.

Cantwell, D.P., Baker, L., \& Mattison, R. (1980). Psychiatric disorders in children with speech and language retardation. Archives of General Psychiatry, 37,423-426.

Carlson, C. (1986). Attention deficit disorder without hyperactivity: A review of preliminary experimental evidence. In B. Lahey \& A. Kazdin (Eds.), Advances in clinical child psychology (Vol. 9). New York, NY: Plenum.

Chelune, G.J., Ferguson, W., Koon, R., \& Dickey, T.O. (1986). Frontal lobe disinhibition in attention 
deficit disorder. Child Psychiatry and Human Development, 16, 221-234.

Conners, C.K. (1985). The computerized continuous performance test. Psychopharmacology Bulletin, 21, 891- 892 .

Cooley, E.I., \& Morris, R.D. (1990). Attention in children: A neuropsychologically based model for assessment. Developmental Neuropsychology, 6, 239-274.

Costello, A.J., Edelbrock, C.S., Kalas, R., Kessler, M., \& Klaric, S. (1982). The NIMH Diagnostic Interview Schedule for Children (DISC). [Unpublished interview schedule.] Pittsburgh, PA: Department of Psychiatry, University of Pittsburgh.

Derogatis, L. (1986). Manual for the Symptom Checklist 90- Revised (SCL-90). Baltimore, MD: Author.

Douglas, V.I. (1983). Attention and cognitive problems. In M. Rutter (Ed.), Developmental neuropsychiatry. New York, NY: Guilford.

DuPaul, G. (1991). Parent and teacher ratings of ADHD symptoms: Psychometric properties in a community based sample. Journal of Clinical Child Psychology, 20, 245-253.

DuPaul, G.J., Anastopoulos, A.D., Shelton, T.L., Guevremont, D.C., \& Metevia, L. (1992). Multimethod assessment of attention deficit hyperactivity disorder: The diagnostic utility of clinic-based tests. Journal of Clinical Child Psychology, 21, 394-402.

Dykman, R.A., \& Ackerman, P.T. (1991). Attention deficit disorder and specific reading disability: Separate but often overlapping disorders. Journal of Learning Disabilities, 24, 96-103.

Edelbrock, C.S. (1985). The Child Attention Problems (CAP) Rating Scale. Unpublished manuscript. Available in Barkley, R.A. (1990). Attention deficit hyperactivity disorder. New York, NY: Guilford.

Ferguson, D.M., \& Horwood, L.J. (1992). Attention deficit and reading achievement. Journal of Child Psychology and Psychiatry, 33, 375-385.

Fowler, M. (1992). Educator's manual. Plantation, FL: CHADD.

Fuster, J.M. (1989). A theory of prefrontal functions: The prefrontal cortex and the temporal organization of behavior. In J.M. Fuster (Ed.), The prefrontal cortex: Anatomy, physiology, and neuropsychology of the frontal lobe. New York, NY: Raven.

Goldman, R., Fristoe, M., \& Woodcock, R.W. (1986). Goldman-Fristoe-Woodcock Test of Auditory Discrimination. Circle Pines, MN: American Guidance Service.

Goodyear, P., \& Hynd, G. (1992). Attention deficit disorder with (ADD/H) and without (ADD/WO) hyperactivity: Behavioral and neuropsychological differentiation. Journal of Clinical Child Psychology, 21, 273-304.

Gordon, M. (1983). The Gordon diagnostic system. Boulder, CO: Clinical Diagnostic Systems.

Goyette, C.H., Conners, C.K., \& Ulrich, R.F. (1978). Normative data for Revised Conners Parent and Teacher Rating Scales. Journal of Abnormal Child Psychology, 6, 221-236.

Gray, J.A. (1982). The neuropsychology of anxiety. New York, NY: Oxford Press.

Greenblatt, E., Mattis, S., \& Trad, P.V. (1991). The ACID pattern and the Freedom from Distractibility Factor in a child psychiatric population. Developmental Neuropsychology, 7, 121-130.

Hale, G.A., \& Lewis, M. (1979). Attention and cognitive development. New York, NY: Plenum.

Hamlett, K.W., Pellegrini, D.S., \& Conners, C.K. (1987). An investigation of executive processes in the problem-solving of attention deficit disorder-hyperactive children. Journal of Pediatric Psychology, 12, 227-240.

Hartsough, C.S., \& Lambert, N.M. (1985). Medical factors in hyperactive and normal children: Prenatal, developmental, and health history findings. American Journal of Orthopsychiatry, 55, 190-201.

Heilman, K.M., Voeller, K.K.S., \& Nadeau, S.E. (1991). A possible pathophysiological substrate of attention deficit hyperactivity disorder. Annals of Neurology, 6, 74-79. 
Hodges, K., Horwitz, E., \& Kline, J. (1982). Comparison of various WISC-R summary scores for a psychiatric sample. Journal of Clinical Psychology, 38, 830-837.

Hodges, K., McKnew, D., Cytryn, L., Stem, L., \& Kline, J. (1982). The Child Assessment Schedule (CAS) diagnostic interview: A report on reliability and validity. Journal of the American Academy of Child Psychiatry, 21, 468-473.

Jacob, R.G., O'Leary, K.D., \& Rosenblad, C. (1978). Formal and informal classroom settings: Effects on hyperactivity. Journal of Abnormal Child Psychology, 6, 47-59.

James, W. (1898). Principles of psychology. Chicago, IL: University of Chicago (Britannica Great Books).

Kagan, J. (1966). Reflection-impulsivity: The generality and dynamics of conceptual tempo. Journal of Abnormal Psychology, 71, 17-24.

Kanfer, F.H., \& Saslow, G. (1969). Behavioral diagnosis. In C.M. Franks (Ed.), Behavior therapy: Appraisal and status. New York, NY: McGraw-Hill.

Kaufman, A.S. (1979). Intelligent testing with the WISC-R. New York, NY: Wiley.

Kendall, P.C., \& Wilcox, L.E. (1979). Self-control in children: Development of a rating scale. Journal of Consulting and Clinical Psychology, 48, 80-91.

Klee, S.H., \& Garfinkel, B.D. (1983). The computerized continuous performance task: A new measure of attention. Journal of the American Academy of Child Psychiatry, 11, 487-496.

Kovacs, M. (1982). The longitudinal study of child and adolescent psychopathology: I. The semistructure psychiatric interview schedule for children (ISC). Unpublished manuscript. Pittsburgh, PA: Western Psychiatric Institute.

Locke, H.J., \& Wallace, K.M. (1959). Short marital adjustment and prediction tests: Their reliability and validity. Journal of Marriage and Family Living, 21, 251-255.

Luk, S. (1985). Direct observations studies of hyperactive behaviors. Journal of the American Academy of Child Psychiatry, 24, 338-344.

McIlvane, W. (1994, January). A theory and model of attention from a behavioral perspective. Paper presented at the NICHD Conference on Attention, Memory, and Executive Functioning. Bethesda, MD: National Institute of Child Health and Human Development.

Mesalum, M.M. (1990). Large-scale neurocognitive networks and distributed processing for attention, language, and memory. Annals of Neurology, 28, 597-613.

McGee, R., Silva, P.A., \& Williams, S. (1984). Perinatal, neurological, environmental, and developmental characteristics of seven-year-old children with stable behaviour problems. Journal of Child Psychology and Psychiatry, 25, 573-586.

Milich, R., \& Kramer, J. (1985). Reflections on impulsivity: An empirical investigation of impulsivity as a construct. In K. Gadow \& I. Bialer (Eds.), Advances in learning and behavioral disabilities (Vol. 3). Greenwich, CT: JAI.

Milich, R., Landau, S., \& Loney, J. (1981, August). The inter-relationships among hyperactivity, aggression, and impulsivity. Paper presented at the annual meeting of the American Psychological Association, Los Angeles, CA.

Mirsky, A.F. (1987). Behavioral and psychophysiological markers of disordered attention. Environmental Health Perspectives, 74, 191-199.

Porrino, L.J., Rapoport, J.L., Behar, D., Sceery, W., Ismond, D.R., \& Bunney, W.E. (1983). A naturalistic assessment of the motor activity of hyperactive boys. Archives of General Psychiatry, 40, 681-687.

Posner, M. (1988). Structures and function of selective attention. In M. Dennis, E. Kaplan, M. Posner, D. Stein, \& R. Thompson (Eds.), Clinical neuropsychology and brain function: Research, 
measurement, and practice. Washington, DC: American Psychological Association.

Pribram, K.H. (1971). Language of the brain: Experimental paradoxes and principles in neuropsychology. Englewood Cliffs, NJ: Prentice Hall.

Quay, H.C. (1988). Attention deficit disorder and the behavioral inhibition system: The relevance of the neuropsychological theory of Jeffrey A. Gray. In L. Bloomingdale \& J. Sergeant (Eds.), Attention deficit disorders: Criteria, cognition, and intervention. New York, NY: Pergamon.

Rapin, I., \& Wilson, B.C. (1978). Children with develop-mental language disability: Neurological aspects and assessment. In M.A. Wyke (Ed.), Developmental dysphasia. New York, NY: Academic Press.

Rapport, M.D., Tucker, S.B., DuPaul, F.J., Merlo, M., \& Stoner, G. (1986). Hyperactivity and frustration: The influence of control over and size of rewards in delaying gratification. Journal of Abnormal Child Psychology, 14, 191-204.

Richman, L.C., \& Lindgren, S.D. (1981). Verbal mediation deficits: Relation to behavior and achievement in children. Journal of Abnormal Psychology, 90, 99-104.

Roberts, M.A. (1987). How is playroom behavior observation used in the diagnosis of attention deficit disorder? In J. Loney (Ed.), The young hyperactive child (pp. 65-74). New York, NY: Hayworth.

Safer, D.J., \& Allen, R. (1976). Hyperactive children. Baltimore, MD: University Park Press.

Shelton, T.L., \& Barkley, R.A. (1993). Assessment of attention-deficit hyperactivity disorder in young children. In J.L. Culbertson \& D.J. Willis (Eds.), Testing young children. Austin, TX: Pro-Ed.

Shiffrin, R.M. \& Schneider, W. (1977). Controlled and automatic human information processing: II. Perceptual and learning, automatic attending, and a general theory. Psychological Bulletin, 84, 127-190.

Skinner, B.F. (1953). Science and human behavior. New York, NY: Macmillan.

Stewart, M.A., Pitts, EN., Carig, A.G., \& Dieruf, W. (1966). The hyperactive child syndrome. American Journal of Orthopsychiatry, 36, 861-867.

Szatmari, P., Offord, D.R., \& Boyle, M.H. (1989). Ontario child health study: Prevalence of attention deficit disorder with hyperactivity. Journal of Child Psychology and Psychiatry, 30, 219-230.

Taylor, E.A. (1986). Childhood hyperactivity. British Journal of Psychiatry, 149, 562-573.

Thorndike, R.L., Hagen, E.P., \& Sattler, J.M. (1986). Guide for administering and scoring the StanfordBinet Intelligence Scale (4th ed.). Chicago, IL: Riverside.

Titchener, E.B. (1924). A textbook of psychology. New York, NY: Macmillan.

Tortolani, B.C., Murray, S., Risucci, D.A., \& Wilson, B.C. (1987). Scales for the assessment of language sample questionnaire (SL1Q). Manhasset, NY: Northshore University HospitalCornell University Medical Center.

Trommer, B.L., Hoeppner, J.B., Lorber, R., \& Amistrong, K. (1988). Pitfalls in the use of a continuous performance test as a diagnostic tool in attention deficit disorder. Developmental and Behavioral Pediatrics, 9, 339-345.

Tryon, W.W. (1984). Principles and methods of mechanically measuring motor activity. Behavioral Assessment, 6, 129-140.

Ullmann, R., Sleator, E., \& Sprague, R. (1984). A new rating scale for diagnosis and monitoring of ADD children. Psychopharmacology Bulletin, 20, 160-164.

van der Meere, J., \& Sergeant, J. (1988). Focused attention in pervasively hyperactive children. Journal of Abnormal Child Psychology, 16, 627-640.

Wechsler, D. (1974). Manual for the Wechsler intelligence scale for children (rev.). San Antonio, TX: The Psychological Corporation.

Wechsler, D. (1989). Manual for the Wechsler preschool and primary scales of intelligence scale for 
children (rev.). San Antonio, TX: The Psychological Corporation.

Wechsler, D. (1991). Manual for the Wechsler intelligence scale for children (3rd ed.). San Antonio, TX: The Psychological Corporation.

Weithorn, C.J., \& Kagen, E. (1978). Interaction of language development and activity level on performance of first-graders. American Journal of Orthopsychiatry, 48, 148- 159.

Werry, J.S., \& Sprague, R.L. (1970). Hyperactivity. In C. G. Costello (Ed.), Symptoms of psychopathology. New York, NY: Wiley.

Wielkiewicz, R.M. (1990). Interpreting low scores on the WISC-R third factor: It's more than distractibility. Psychological Assessment, 2, 91-97.

Wilson, B.C., \& Risucci, D.A. (1986). A model for clinical-quantitative classification: Generation 1: Application to language-disordered preschool children. Brain and Language, 27, 281-309.

Woodcock, R.W., \& Johnson, M.B. (1990). Woodcock—Johnson psycho-educational battery (rev.). Allen, TX: DLM Teaching Resources.

Zametkin, A.J., \& Rapoport, J.L. (1986). The pathophysiology of attention deficit disorder with hyperactivity: A review. In B. Lahey \& A. Kazdin (Eds.), Advances in clinical child psychology (Vol. 9). New York, NY: Plenum.

Zentall, S.S. (1985). A context for hyperactivity. In K.D. Gadow \& I. Bialer (Eds.), Advances in learning and behavioral disabilities (Vol. 4). Greenwich, CT: HAI Press.

Zentall, S.S. (1989). Production deficiencies in elicited language but not in the spontaneous verbalization of hyperactive children. Journal of Abnormal Child Psychology, 16, 657-673.

Zettle, R.D., \& Hayes, S.C. (1982). Rule-governed behavior: A potential theoretical framework for cognitive-behavioral therapy. Advances in cognitive-behavioral research (Vol. 1). New York, NY: Academic Press. 